\title{
Looking forward
}

Michael N. Evans ${ }^{1}$, W. Tinner², Z. Jian³, B. Vannière ${ }^{4}$, S. Eggleston ${ }^{5}$ and M.-F. Loutre ${ }^{5}$

The future of PAGES is in the construction of a more global and diverse paleoscience community, expansion of links with other, complementary initiatives, and in the support of community-driven science. PAGES should challenge itself with bold new initiatives, lean administration, a smaller carbon footprint, and open and inclusive activities, with the central theme of time threaded through the effort.

What will the PAGES community do in its next phase? May we borrow your crystal ball? Our view of PAGES is, at best, educated guesswork but is informed by the trajectory that is evident in the timeline of PAGES activities, achievements, support over the past 30 years (Fig. 1), as well as recent initiatives. The future may also be reflected in the new science and organizational diagram that we present here and which replaces the venerable PAGES triangle (adopted in 2015), and, before that, the science plan and implementation strategy of 2009 (Fig. 2).

\section{Science}

With its unique perspective and focus on the element of time within Earth system dynamics, the PAGES community will continue the development of process understanding by the integrated analysis of experiments, observations, and reconstructions (What

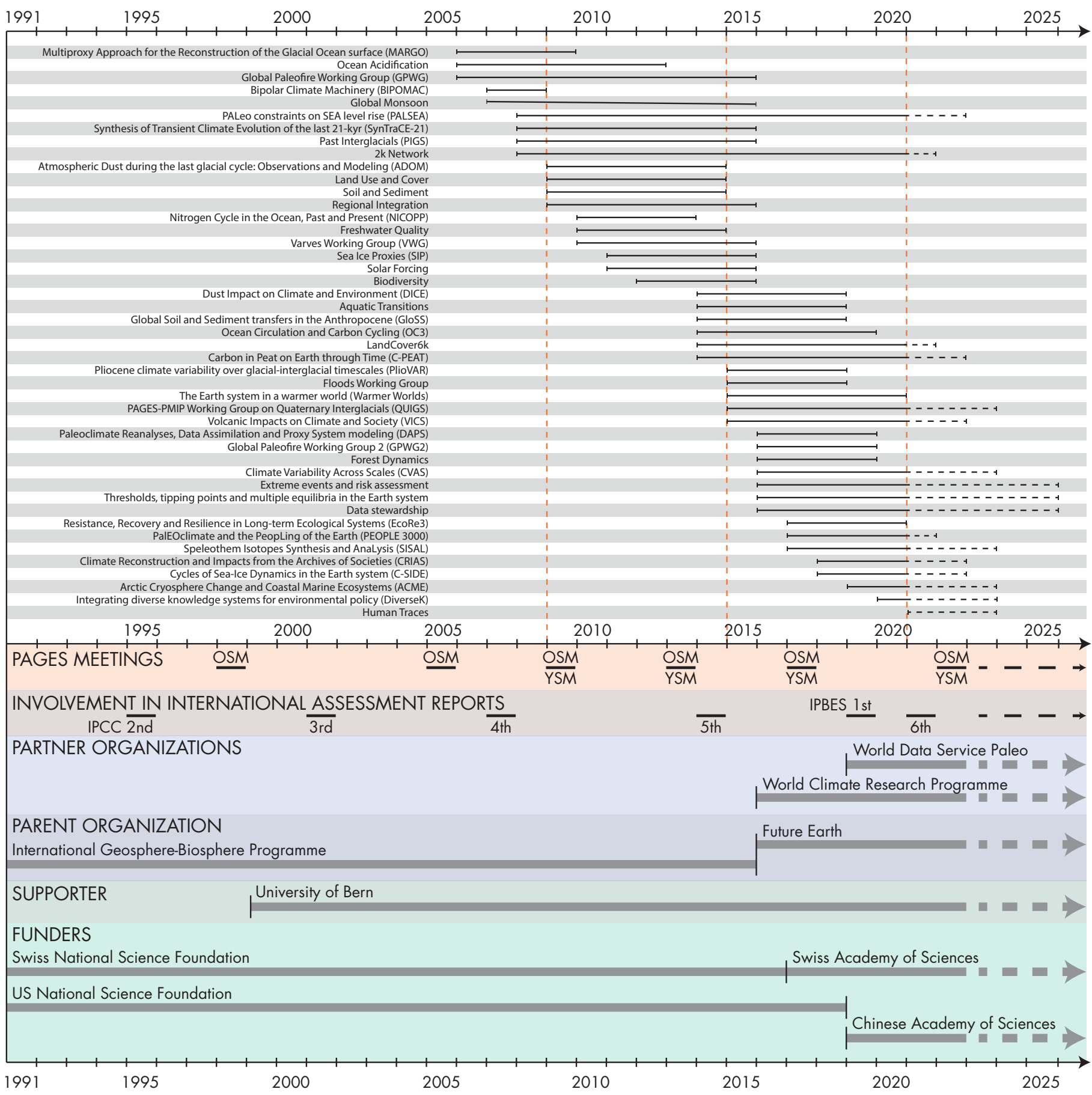

Figure 1: Timeline of PAGES' research themes, working groups, contributions to other global research activities, and funding. Vertical lines represent structural transitions. 

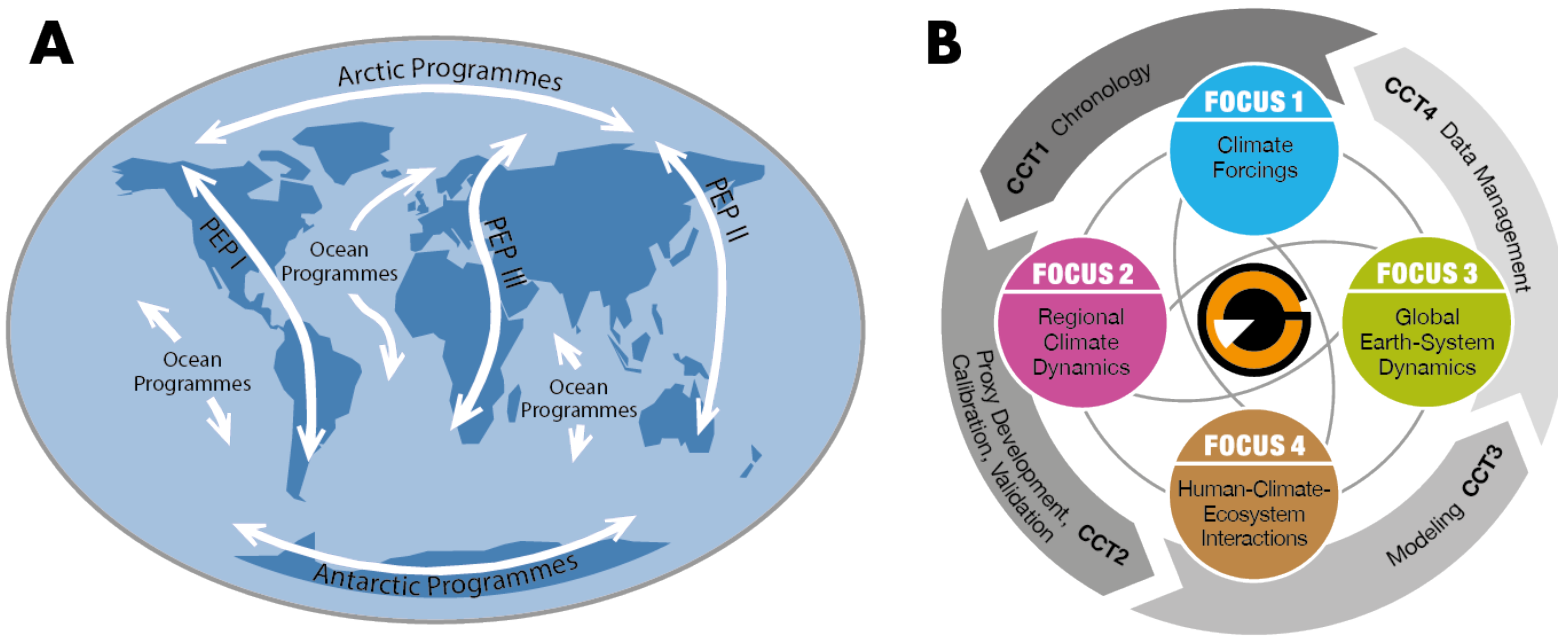

Figure 2: PAGES' scientific structure (A) 1994-1998; (B) 2009-2014 (2015-2021: see Fischer et al. this issue, Fig. 3).

happened? What is possible? How likely is it?) with simulations (Why did it happen? Can it be generated from known processes? How likely is it?). What mechanisms are most consistent with observations, reconstructions, and available simulations that arise from a variety of different experimental designs? Leveraging the increasing precision and accuracy of multivariate data streams and increasingly realistic Earth system simulations, we see PAGES' working groups moving from analysis of global means to regionally resolved patterns. We see renewed focus on moisture dynamics and integrated tracers, climate services, the understanding of ecosystem dynamics, and the ways in which the oceans, atmosphere, land surface, ice, biosphere, and human activities are transiently coupled on timescales of decades to centuries (Fig. 3). These initiatives are already happening. All are useful contributions that enable forecasting of Earth system changes over the extended time horizon of the next ca. 500 years.

\section{Support}

PAGES is extremely fortunate to have had dedicated, continuous support over the past 30 years, including from the US and Swiss National Science Foundations, the Swiss and Chinese Academies of Sciences, and the University of Bern. The effect of steady funding has been cumulative, helping to increase PAGES' momentum, as can be observed in the rise in the number and diversity of supported products. In the next 30 years, PAGES may seek more diverse international support to become deeply rooted on all continents through various national funding instruments. It is up to all scientists involved in PAGES' activities to explore new funding possibilities, such as those currently provided by the Swiss and Chinese Academies of Sciences, in their countries of

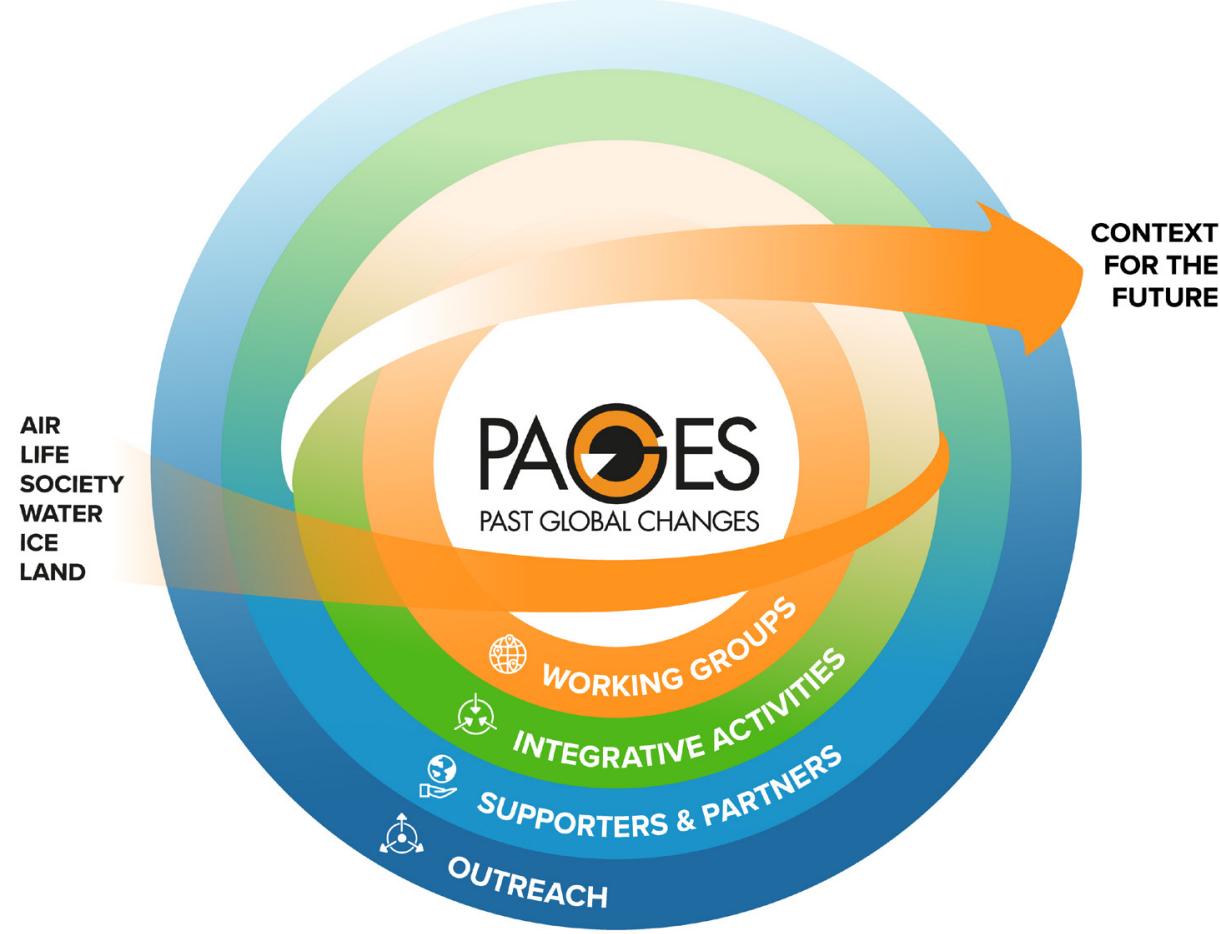

Figure 3: PAGES' proposed new science diagram (2021-). Concentric circles represent the building blocks of PAGES, which at its core is composed of working groups and integrative activities within PAGES' scope. Their research supports partner programs, informs strategies for sustainability, and provides outreach opportunities. The arrow represents the integration of information and learning that propels the paleosciences forwards and provides context for future projections.

residence, to secure and promote PAGES' future prosperity.

\section{Mission}

PAGES' objectives ${ }^{1}$ continue to center on the natural sciences but evolve toward inclusion of social-science perspectives, with continued support for climate, ecosystem and land use reconstructions to discover past processes and mechanisms of environmental and societal dynamics. PAGES' working groups will continue to provide quantitative forcing and long-term data for model validation. To further strengthen the societal perspective, PAGES fosters the development of working groups that seek to more fully integrate social-science disciplines and societal archives, including those from Indigenous records, and of climatic events and their impacts. For example, we might begin to understand the reasons underlying the human imprint on the environment, and this might support the development of the element of time in integrated assessment simulations (Beckage et al. 2018). With input from practitioners, the potential for paleo-informed policy should improve. This trend is evident in the scope of integrative activities on warm state climates and societal risks associated with thresholds and extreme events.

\section{Activities}

PAGES will continue to be communitydriven, with the support of its lean, efficient, and productive International Project Office. This includes even more global collection, dissemination, and synthesis across spatial and temporal scales, for phenomenologically meaningful regions and dimensions (e.g. patterns within and across elements in Fig. 3) by means of Open Science Meetings ${ }^{2}$ and clustered meetings, in which multiple working groups convene to consider shared interests and opportunities, such as the Topical Science Meetings. ${ }^{3}$ Although we acknowledge that personal contacts are at the heart of international science, we anticipate that meetings will become more and more internet-enabled, and virtual, to reduce their carbon footprint. This will enhance the goals of building a community, but also improve accessibility, which is especially important for an increasingly global PAGES. 
It remains a challenge to make PAGES a truly global and diverse community, and to improve the representation of that community in its leadership. Emerging initiatives include visiting fellowships designed to mentor and support African and Latin American scientists; bias training and measures to enable us all to feel safe and welcomed at PAGES Open Science Meetings; web-enabled, recorded, and close-captioned meetings and webinars; and in-person workshops held in a more diverse set of locales. We must lead more in these regards, because it has been the community which has not only created awareness of problems, but also contributed ideas and initiatives to improving PAGES for all.

Further activities will continue to follow FAIR (findable, accessible, interoperable and reusable) practices in the curation and stewardship of paleodata, metadata, and code compilations. This will be achieved through the use of public repositories, advanced databasing technologies, webinars, and partnerships with associated and complementary global research networks such as the NCEI ${ }^{4}$, Neotoma ${ }^{5}$, Linked Earth ${ }^{6}$, PANGAEA ${ }^{7}$, Future Earth ${ }^{8}$, and WCRP. ${ }^{9}$ An achievable goal in the coming decades is the development of self-updating repositories that contain not only raw observations but also dynamic chronologies, reconstructions, and version-tracking code bases, which are indexed to associated direct observations and simulations of phenomena of interest.

Perhaps PAGES' most consequential future activities will be in the development of early-career scientists. Many of us can recall a pivotal PAGES "moment"; for one of us (MNE), it was observing a 2011 2k Network meeting, and leaving an hour or so later with the mandate to start Ocean2k. The PAGES Early-Career Network $\left(E C N^{10}\right)$ has recently formalized the interests and needs of emerging paleoscientists, and its dynamic, virtual community is a model for future working groups. PAGES' Scientific Steering Committee (SSC ${ }^{11}$ ) now encourages working groups to actively engage ECRs in their leadership, and includes an ECR representative on the SSC; this has improved its vision and creativity. PAGES' ECRs and workshop organizers have long integrated outreach activities, such as public events, but we envision a clear need to connect more directly with the public who supports our research and is interested in the science and consequences of global change. To this end, Past Global Changes Horizons (Fig. 4), a magazine for anyone interested in paleoscience, is designed to communicate and educate.

\section{Prospects}

The ultimate goal of PAGES will remain its interest in three challenging global problems: climate change, biodiversity loss, and the sustainability of ecosystems and societies. To succeed, PAGES will need an even better integration of observations and reconstructions with process-based dynamic models to further understand long-term Earth system processes and how they impact sustainability. Additional effort will be needed to train new generations of paleoscientists and transfer knowledge from the PAGES community to the public and to decision-makers. And PAGES has an opportunity and important role to fulfill as its parent body, Future

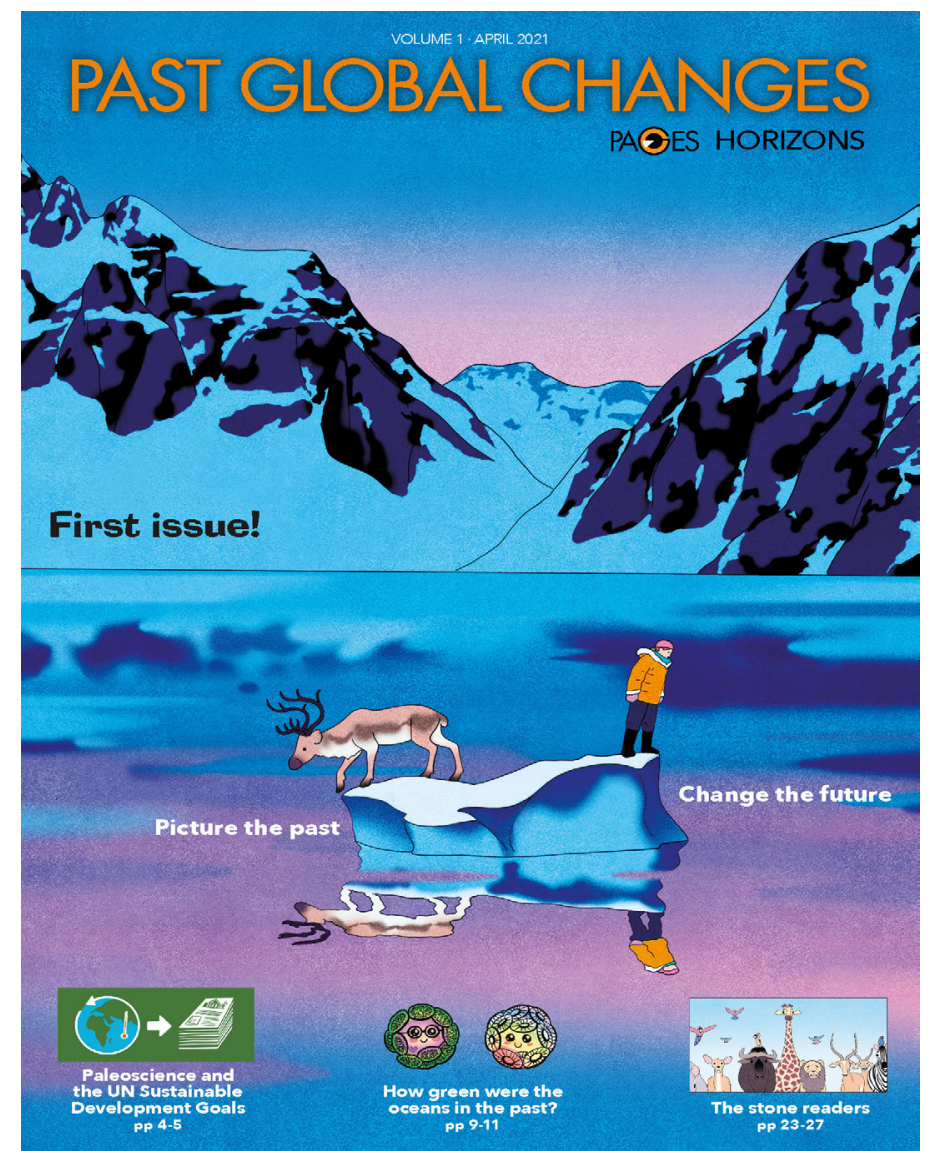

Figure 4: The first issue of PAGES' new magazine for anyone interested in paleoscience, Past Global Changes

Horizons, was published in April 2021. ${ }^{19}$

Earth, evolves. Future Earth's organization is becoming increasingly flat, simple, and representative, reflecting the wide range of ideas present in the community. Within that community, we imagine that PAGES will find synergies with other Future Earth Global Research Projects, such as AIMES ${ }^{12}$, BioDISCOVERY ${ }^{13}$, GMBA $^{14}$, IHOPE $^{15}$, SOLAS $^{16}$ $M R I^{17}$, the Emergent Risk and Extreme Events Knowledge Action Network ${ }^{18}$, and partners such as WCRP.' PAGES can provide observations and modeling of what is possible on the seasonal to multi-million-year timescales that bracket those over which anthropogenic Earth system forcing are likely to be expressed. PAGES can also place concepts of risk, adaptation, resilience, and sustainability of societies within the context of what human civilizations have already managed, and the mechanisms by which they have either succeeded or failed. How might we learn from those past global changes, challenges, successes, and failures? Future global changes may not repeat past global changes, but perhaps they rhyme with them (Wittreich 1987; Gould 1988).

\section{AFFILIATIONS}

'Department of Geology and Earth System Science Interdisciplinary Center, University of Maryland, College Park, US

Institute of Plant Sciences, University of Bern, Switzerland

${ }^{3}$ State Key Laboratory of Marine Geology, Tongji University, Shanghai, China

${ }^{4} \mathrm{MSHE}, \mathrm{CNRS}$, Université Bourgogne Franche-Comté, Besançon, France

${ }^{5}$ PAGES International Project Office, Bern, Switzerland

\section{CONTACT}

Michael N. Evans: mnevans@umd.edu

\section{REFERENCES}

Beckage B et al. (2018) Nat Clim Change 8: 79-84

Gould SJ (1988) Time's Arrow, Time's Cycle: Myth and Metaphor in the Discovery of Geological Time. Harvard University Press, $222 \mathrm{pp}$

Wittreich J (1987) Feminist Milton. Cornell University Press, $192 \mathrm{pp}$

LINKS

1http://pastglobalchanges.org/about/mission

2https://pages-osm.org

${ }^{3} \mathrm{http}: / /$ pastglobalchanges.org/tsm

${ }^{4}$ https://www.ncdc.noaa.gov/data-access/

paleoclimatology-data

5https://www.neotomadb.org

${ }^{6} \mathrm{http}: / /$ linked.earth

7https://pangaea.de

${ }^{8}$ https://futureearth.org

'https://www.wcrp-climate.org

${ }^{10} \mathrm{http}: / /$ pastglobalchanges.org/ecn

${ }^{11} \mathrm{http}: / /$ pastglobalchanges.org/about/structure/

scientific-steering-committee

${ }^{12}$ https://aimesproject.org

${ }^{13} \mathrm{https}$ ///futureearth.org/networks/ global-research-projects/biodiscovery

${ }^{14} \mathrm{https}: / /$ futureearth.org/networks/

global-research-projects/

gmba-global-mountain-biodiversity-assessment

${ }^{15} \mathrm{https} / / /$ futureearth.org/networks/

global-research-projects/

ihope-integrated-history-and-future-of-people-on-earth

${ }^{16} \mathrm{https}$ ///futureearth.org/networks/

global-research-projects/

solas-surface-ocean-lower-atmosphere-study

${ }^{17}$ https://www.mountainresearchinitiative.org

${ }^{18} \mathrm{https} / / /$ futureearth.org/networks/

knowledge-action-networks/risk

${ }^{19} \mathrm{http}: / /$ pastglobalchanges.org/products/pages-horizons 